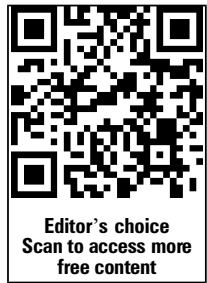

${ }^{1}$ Department of Paediatric Dentistry, College of Dental Science \& Research Center, Ahmedabad, Gujarat, India ${ }^{2}$ Department of Pedodontics \& Preventive Dentistry, Dr R Ahmed Dental College \& Hospital, Kolkata, West Bengal, India

${ }^{3}$ Department of Conservative Dentistry \& Endodontics, AECS Maruti Dental College, Kolkata, West Bengal, India

\section{Correspondence to} Dr Cheranjeevi Jayam, cheranjeevij@gmail.com

Accepted 23 May 2014

CrossMark

To cite: Jayam C, Mitra $\mathrm{M}_{\text {, }}$ Bandlapalli A, et al. BMJ Case Rep Published online: [please include Day Month Year] doi:10.1136/bcr-2013201041

\title{
Aggressive dentigerous cyst with ectopic central incisor
}

\author{
Cheranjeevi Jayam, ${ }^{1}$ Malay Mitra, ${ }^{2}$ Anila Bandlapalli, ${ }^{3}$ Biswanath Jana ${ }^{2}$
}

\begin{abstract}
SUMMARY
Dentigerous cysts form from accumulation of fluid between reduced enamel epithelium and the crown of an unerupted tooth. They cause several difficulties such as swelling, non-eruption of the involved teeth, and displacement of adjacent teeth, and thus require early detection and prompt treatment. Treatment ranges from marsupialisation to enucleation. Enucleation is rarely used in children compared with marsupialisation. This paper discusses successful use of enucleation for treating a dentigerous cyst and explains the need for such a radical procedure.
\end{abstract}

\section{BACKGROUND}

Dentigerous cyst arises through accumulation of fluid between reduced enamel epithelium and the crown of an unerupted tooth. ${ }^{1}$ Inflammatory dentigerous cyst is a type of dentigerous cyst that is found in relation to successor teeth with pulpally involved primary teeth. Dentigerous cysts cause a variety of problems, such as swelling due to bone expansion, impaction of involved teeth, displacement of adjacent teeth and structure, and are sometimes associated with carcinomatous transformation. ${ }^{1}{ }^{2}$ In children, conservative treatment such as marsupialisation is undertaken because it is least invasive, it preserves the tooth, and there is potential for the tooth to erupt into the cavity. However, enucleation should be considered in situations where cysts are large causing severe destruction of adjacent structures or they show carcinomatous potential. ${ }^{2}$ The present paper discusses use of the more radical treatment, 'enucleation'.

\section{CASE PRESENTATION}

An 11-year-old girl presented with a swelling in the left upper jaw. She had suffered occasional pain for 1 month, and the swelling had appeared in the preceding week. Intraoral examination showed a very large swelling in the left maxilla and palate region extending from midline to maxillary first molar anteroposteriorly and labial cortex to lingual cortex transversely measuring approximately $6 \mathrm{~cm} \times 3 \mathrm{~cm}$ (figure 1). Bimanual palpation revealed that the swelling was hard in consistency with egg crackling in the region of teeth 21 and 22 labially. The swelling had caused expansion of both labial and palatal cortices. Borders were indistinct. Over-retained teeth 61, 62 and 63 showed preshedding mobility, and the absence of the corresponding successors 21, 22 and 23 was noticed in comparison with erupted teeth 11,12 and 13 on the right side. Tooth 61 showed carious involvement of

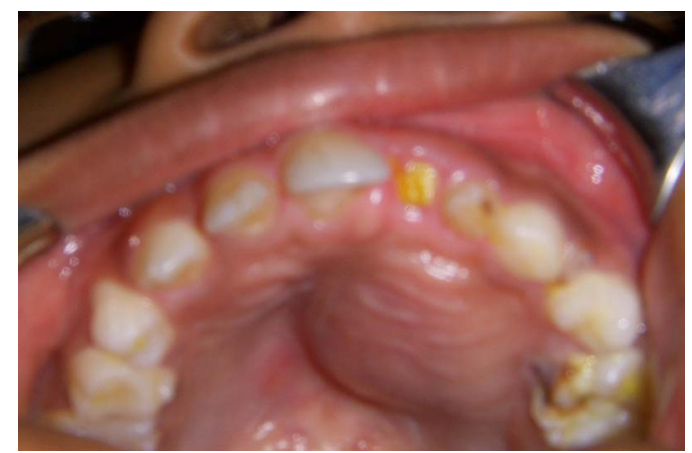

Figure 1 Intraoral preoperative view.

pulp. A provisional diagnosis of inflammatory dentigerous cyst was considered. Intraoral periapical, occlusal and orthopantomographic views were advised (figures 2 and 3).

\section{DIFFERENTIAL DIAGNOSIS}

Differentially to inflammatory dentigerous cyst, a diagnosis of radicular cyst was considered for the following reasons. Clinically, there was the presence of a swelling in the buccal aspect surrounding the pulpally involved (over-retained) primary central incisor (tooth 61). Using radiographic findings, a

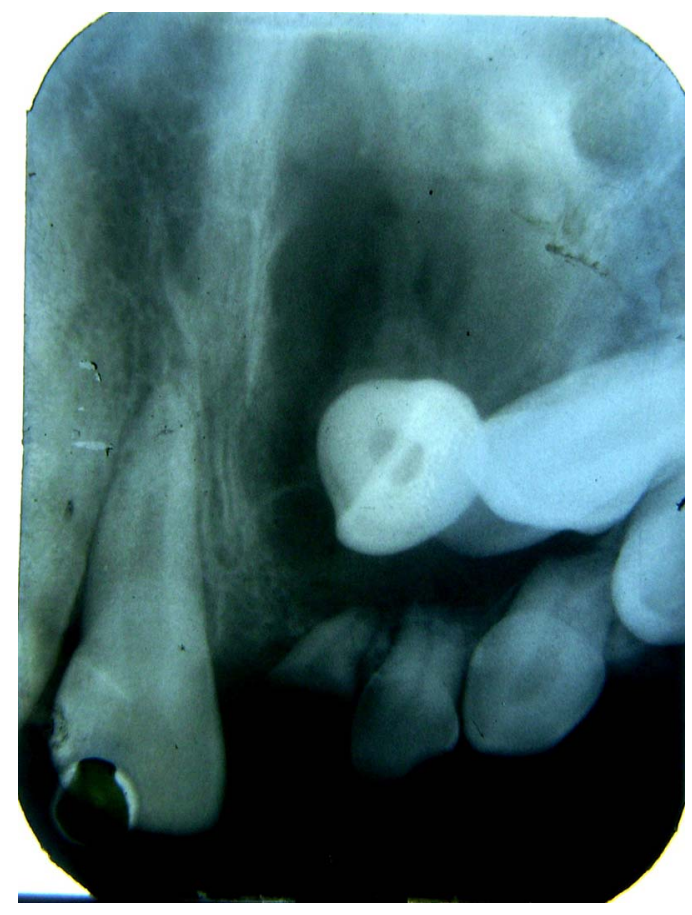

Figure 2 Intraoral periapical view. 




Figure 3 Occlusal view.

well-defined radiolucency was evident on all the X-ray views, suggestive of a radicular cyst arising from tooth 61 .

\section{INVESTIGATIONS}

Notable radiographic findings included the presence of very large area of unilocular radioluceny extending from midline to maxillary first molar, expansion of the buccal cortical plate, ectopically displaced teeth 21, 22 and 23, and retained teeth 61, 62 and 63. Cystic fluid aspiration showed straw-coloured fluid, and laboratory analysis found a protein content similar to dentigerous cyst and a large amount of inflammatory cells. On the basis of the amount of displacement of the adjacent teeth, expansion of the cortical plate, and cystic fluid analysis, the diagnosis was tending towards inflammatory dentigerous cyst rather than radicular cyst, which was later confirmed by histopathological examination of the cyst wall and its contents.

\section{TREATMENT}

A mucoperiosteal flap was carefully planned and raised considering the large extent of the lesion to provide good access. Teeth 61, 62 and 63 were extracted. During cyst removal, care was taken to prevent openings into the nasal or oral cavity. The cyst was excised in its entirety leaving behind a large residual cavity (figure 4). During cyst enucleation, it was noted that

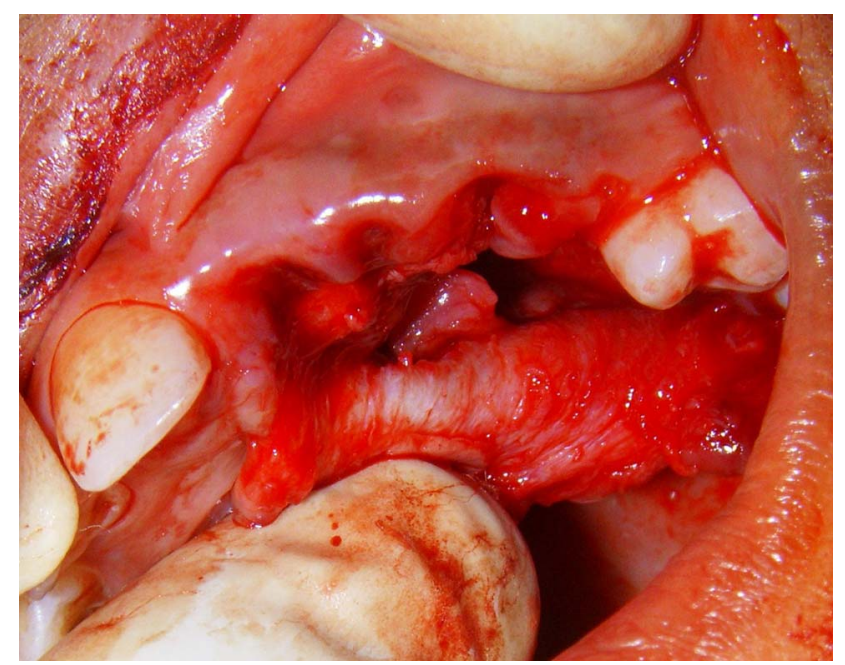

Figure 4 Intraoral perioperative view.

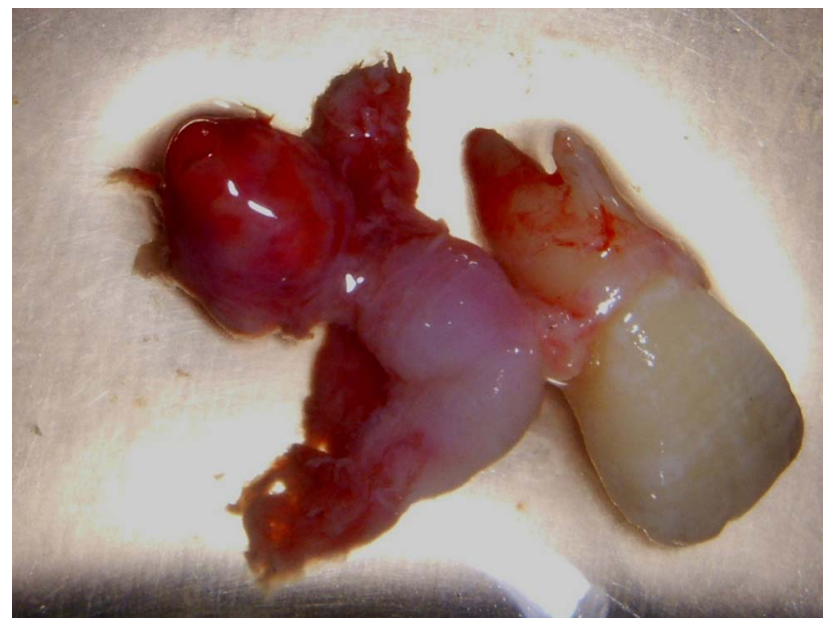

Figure 5 Extracted tooth and excised cystic tissue.

preservation of tooth 21 would be difficult and that it would require extraction for the following reasons: (a) the tooth was greatly displaced; (b) unfavourable angulations for eruption; (c) the absence of bone in the residual cavity would jeopardise tooth vitality; and (d) transplantation was not possible because of the absence of neighbouring bone (figure 5). However, teeth 22 and 23 showed good angulations and adequate bone in that area, thus a decision was taken to retain these teeth and check for spontaneous eruption. Collagen gel foam was placed in the residual cavity to allow primary closure and to eliminate the large defect (figure 6). A post-surgical stent was placed to allow good healing and prevent haematoma formation (figure 7). Since the lesion was large, two different areas of cystic lesion were sent for histopathological study to rule out any malignancy. The histopathological report confirmed our diagnosis of inflammatory dentigerous cyst (figure 8). A removable partial denture is provisionally planned for edentulousness and will be replaced with a permanent fixed partial denture after eruption of teeth 22 and 23 and appropriate settling of the occlusion.

\section{Histopathology}

The cystic lining showed the presence of 3-4-cell-layer-thick, stratified, squamous, non-keratinised epithelium and a few islands of parakeratin, which is characteristic of the

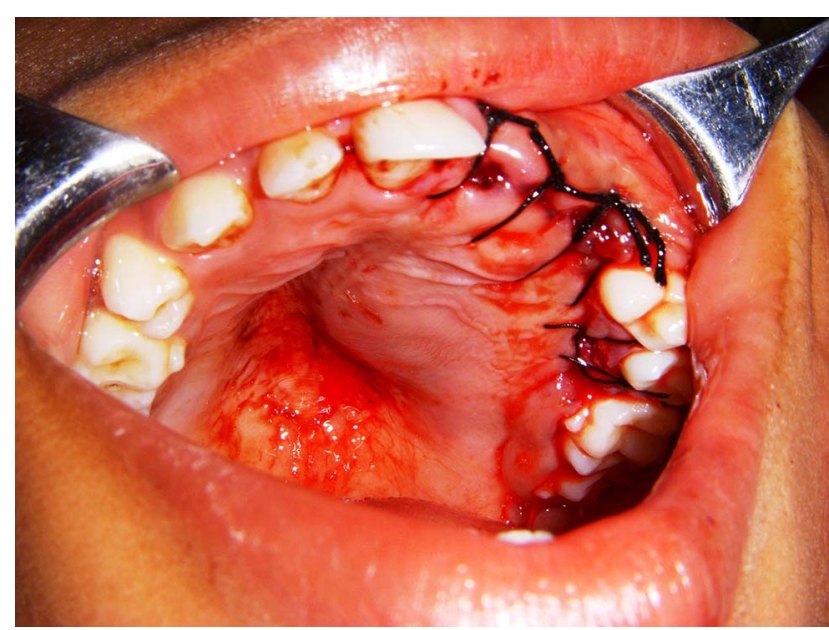

Figure 6 Intraoral postoperative view. 


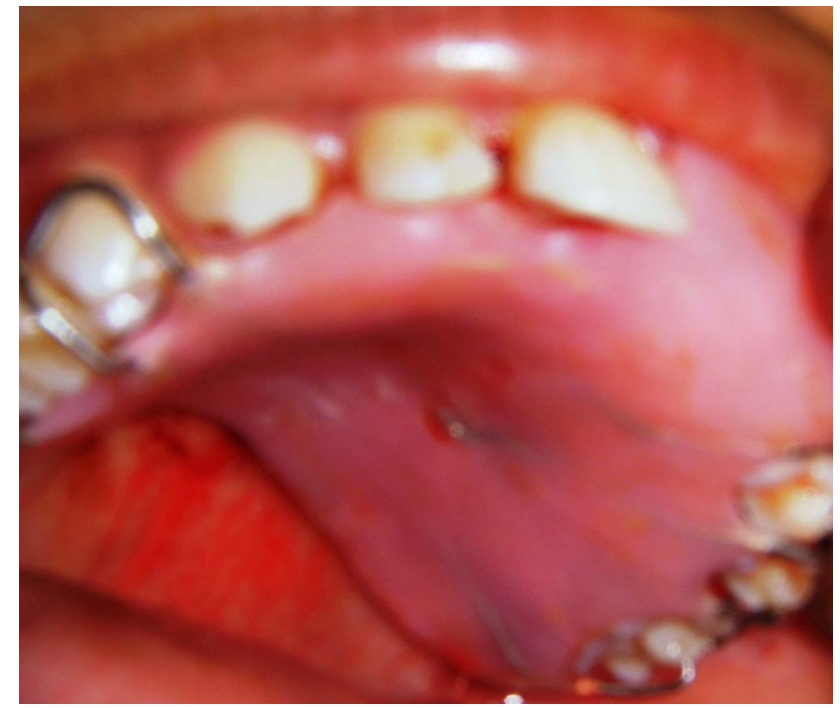

Figure 7 Surgical stent in position.

inflammatory type of dentigerous cyst. The cyst wall contained a few polymorphonuclear cells and a few cholesterol clefts.

\section{OUTCOME AND FOLLOW-UP}

The patient was followed until proper permanent dental rehabilitation.

\section{DISCUSSION}

A dentigerous cyst of inflammatory origin results when inflammation from pulpally involved primary teeth act as a stimulating factor, allowing accumulation of fluid between the reduced enamel epithelium and the unerupted successor crown. ${ }^{12}$ So these cysts are commonly seen during the first and second decade of life (mixed dentition period). ${ }^{4}$ Dentigerous cysts account for $\sim 15 \%$ of all jaw cysts. They are more common in boys than girls, and there is no preference for a specific race or ethnicity. They are more commonly found in the mandible than maxilla. Teeth commonly involved are third molars, followed by canines and second premolar. Dentigerous cysts of inflammatory origin always present a diagnostic dilemma radiographically. ${ }^{4}{ }_{5}$ Radiographically, an inflammatory dentigerous cyst is seen as pericoronal unilocular radiolucency attached at the cemento-enamel junction of the



Figure 8 Histopathology of cystic lining. impacted tooth and in continuation with the lamina dura of the deciduous tooth. ${ }^{6}$ Because of these features, it is commonly confused with radicular cyst. Histopathology is a good investigation to differentiate between inflammatory dentigerous cyst and radicular cyst. Treatment for inflammatory dentigerous cysts of succedaneous teeth in mixed dentition include: (a) extraction of infected primary teeth to allow spontaneous eruption of successor teeth; (b) marsupialisation; (c) cyst enucleation with extraction of permanent teeth. ${ }^{3}$ In children, the first two treatment modalities are preferred because they are surgically less invasive and preserve the successor teeth. ${ }^{7}$ Other important factors that favour marsupialisation are young age, psychology to undergo surgery, stage and position of tooth development, position of tooth, eruption potential and space availability. ${ }^{8-10}$ Importantly, treatment in children should aim to save developing successor teeth without sacrificing the successor teeth. However, cyst enucleation and extraction of the successor is sometimes advised. Enucleation is advised when (a) cysts are large and aggressive, (b) the tooth is displaced to such an extent that it cannot be moved to the correct position in the dental arch, (c) there is damage to adjacent structures, and (d) there are malignant changes in the cyst. ${ }^{11} 12$ In the present case, enucleation of the cyst and extraction of the tooth was more appropriate treatment for tooth 21 because displacement of the tooth prevented it being moved into the arch, the cyst was very large, there was loss of large amounts of alveolar bone causing a hallow alveolus, and bone loss also prevented transplantation of the tooth. All these factors favoured enucleation and extraction rather than the marsupialisation treatment that was contemplated for teeth 22 and 23.

\section{Learning points}

- For dentigerous cysts in children, treatment should not just be limited to marsupialisation, but should be based on various factors such as: (1) age of patient; (2) type of dentition; (3) site of lesion; (4) size of lesion; (5) ability of teeth to erupt into oral cavity; (6) displacement and resorption of adjacent tissues; (7) carcinomatous potential.

- Early detection of cyst is necessary to prevent or intercept its deleterious effects.

- Careful scruitinising of routine radiographs taken during developmental periods can detect cystic changes during early stages.

Competing interests None.

Patient consent Obtained.

Provenance and peer review Not commissioned; externally peer reviewed.

\section{REFERENCES}

1 Marwah N, Bishen KA, Prabha V, et al. A conservative approach in the management of inflammatory dentigerous cyst in transitional dentition: a case report. J Mass Dent Soc 2012;61:18-21.

2 Zapała-Pośpiech A, Wyszyńska-Pawelec G, Adamek D, et al. Malignant transformation in the course of a dentigerous cyst: a problem for a clinician and a pathologist. Considerations based on a case report. Pol J Pathol 2013;64:64-8.

3 Hegde RJ, Khare SS, Devrukhkar VN. Dentigerous cyst in a young child: clinical insight and a case report. J Indian Soc Pedod Prev Dent 2013;31:209-11.

4 Asnani S, Mahindra U, Rudagi BM, et al. Dentigerous cyst with an impacted third molar obliterating complete maxillary sinus. Indian J Dent Res 2012;23:833-5.

5 Benn A, Altini M. Dentigerous cysts of inflammatory origin. A clinic-pathologic study. Oral Surg Oral Med Oral Pathol Oral Radiol Endod 1996;81:203-9.

6 Narang RS, Manchanda AS, Arora P, et al. Dentigerous cyst of inflammatory origin: a diagnostic dilemma. Ann Diagn Pathol 2012;16:119-23. 
7 Schafer WG, Hine MK, Levy BM. Cysts \& tumors of odontogenic origin. Textbook of oral pathology. 4th edn. WB Saunders, 2003: 258-318.

8 Kirtaniya BC, Sachdev V, Singla A. Marsupialization: conservative approach for treating dentigerous cyst in children in the mixed dentition. J Indian Soc Pedod Prev Dent 2010;28:203-8.

9 Shivaprakash PK, Rizwanulla T, Baweja DK, et al. Save-a-tooth: conservative surgical management of dentigerous cyst. J Indian Soc Pedod Prev Dent 2009:27:52-7.
10 Shashikiran ND, Kumar NC, Reddy VV. Unusual presentation of inverted impacted premolars as a result of dentigerous cyst: a case report. J Indian Soc Pedod Prev Dent 2006:24:97-9.

11 Aggarwal P, Saxena S. Aggressive growth and neoplastic potential of dentigerous cysts with particular reference to central mucoepidermoid carcinoma. $\mathrm{Br} J$ Oral Maxillofac Surg 2011;49:36-9.

12 Moosvi Z, Tayaar SA, Kumar GS. Neoplastic potential of odontogenic cysts. Contemp Clin Dent 2011;2:106-9.

Copyright 2014 BMJ Publishing Group. All rights reserved. For permission to reuse any of this content visit http://group.bmj.com/group/rights-licensing/permissions.

BMJ Case Report Fellows may re-use this article for personal use and teaching without any further permission.

Become a Fellow of BMJ Case Reports today and you can:

- Submit as many cases as you like

- Enjoy fast sympathetic peer review and rapid publication of accepted articles

- Access all the published articles

- Re-use any of the published material for personal use and teaching without further permission

For information on Institutional Fellowships contact consortiasales@bmjgroup.com

Visit casereports.bmj.com for more articles like this and to become a Fellow 